\title{
Retraction Note to: Feature extraction method of stress distribution in indoor load-bearing buildings
}

\author{
Hang Deng ${ }^{1}$
}

Published online: 6 December 2021

(c) Saudi Society for Geosciences 2021

Retraction Note to: Arabian Journal of Geosciences (2021) 14: 1358 https://doi.org/10.1007/s12517-021-07723-x

The Editor-in-Chief and the Publisher have retracted this article because the content of this article is nonsensical. The peer review process was not carried out in accordance with the Publisher's peer review policy. The author has not responded to correspondence regarding this retraction.

The original article can be found online at https://doi.org/10.1007/ s12517-021-07723-x.

Hang Deng

rr6977rr@163.com

1 School of Road Bridge and Architecture, Chongqing

Vocational College of Transportation, Chongqing 400000,

China 